\title{
A Comparative Study on Engagement Resources in American and Chinese CSR Reports
}

\author{
Chen Pinying ${ }^{1}$ \\ ${ }^{1}$ School of Graduate, Xi'an International Studies Universities, Xi'an, Shaan'xi, P. R. China \\ Correspondence: Chen Pinying, School of Graduate, Xi'an International Studies University, Xi'an, Shaan'xi, P. \\ R. China. Tel: 181-9202-5635. E-mail: chenpinying115@126.com
}

Received: August 29, 2018 Accepted: October 13, 2018 Online Published: October 16, 2018

doi: 10.5539/elt.v11n11p122 URL: http://doi.org/10.5539/elt.v11n11p122

\begin{abstract}
Based on Martin and White's (2005) heteroglossic engagement system of Appraisal Theory, adopting UAM Corpus Tool and Chi-Square test, this study aims to explore authorial stance and distinctive rhetorical strategies that have been employed to realize interpersonal meaning by the application of engagement resources in American and Chinese CSR reports. It can be concluded that all types of engagement resources are widely employed in both American and Chinese corpus, with contraction resources significantly different in two corpora. It also finds that American CSR reports employ each type of engagement markers equally, while Chinese CSR reports tend to highly use expansion resources to enhance authorial voice. Besides, American CSR reports employ contraction resources in a more diversified and flexible way than Chinese CSR reports writers do. Lastly, they are also different in acknowledging what kinds of external propositions as expansion resources. This study confirms that engagement system is an important tool to help CSR reports writers to align authorial voices with readers, thereby accomplishing promotional and persuasive purposes. It may give some implications to CSR report addressers, addressees, business English teaching and reading.
\end{abstract}

Keywords: engagement resources, interpersonal meaning, corporate social responsibility report, comparative study

\section{Introduction}

The release of corporate social responsibility report (hereafter CSR report) involves CSR communication between corporations and stakeholders (Podnar, 2008). CSR report covers a wide range of issues from carbon footprints to human rights, and concerns various stakeholders such as investors, communities, employees etc. The initial aim of producing CSR report is to ensure more transparent business operation and to enable a more democratic social order (Gray, 2006; Spence, 2009). Besides, Hyland (2005) pointed out that letters to shareholders in business reports is an ostensibly informative genre which lists out the information and seemingly objective evaluation of the company's activities, performance and future plans (p. 74). Furthermore, corporate report indicates the marketing of corporate ideology. Therefore, it is not surprising to hold the view that CSR report, a subgenre of business reports, is not only used as a main tool to legitimize CSR information, but also to achieve more important interpersonal functions such as building credibility, persuading putative readers, maintaining positive corporate image etc.

This paper focuses on how the writers of CSR reports posit their authorial stance to involve putative readers and to appropriately impart interpersonal meaning of CSR reports to readers. By comparing distribution of engagement markers in American and Chinese CSR reports, it is expected to find differences in rhetorical strategies that CSR reports writers adopt to enhance authorial stance and align themselves with readers, thereby accomplishing promotional and persuasive functions. It may suggest that Chinese CSR reports writers employ the integration of engagement markers as strategically as American writers do so that CSR reports of Chinese listed companies can be much more easily comprehended by stakeholders and accepted by wider international investors. Besides, it may shed light on ESP researchers and teachers.

\section{The Related Studies}

\subsection{The Genre of CSR Report}

CSR report, also known as Sustainability Report or Citizenship Report, is produced to provide non-financial 
information of a company in the area of business performance, environment, community, marketplace and workplace (Hackston \& Milne, 1996). In order to institutionalize CSR reporting, a number of organizations and initiatives have developed global standards to regulate CSR reports, such as the Global Reporting Initiative (GRI) and the United Nations Global Compact (UNGC). CSR report is issued either as a part of annual report or as a standalone report (Eccles \& Krzus, 2010). In response to social challenges and diversified stakeholders' expectations, more and more companies begin to disclose their standalone CSR report voluntarily. Therefore, standalone CSR report becomes increasingly popular in business communication field.

CSR report, the newcomer of "colony of reporting genre" (Bhatia, 2008a, p.168), is used as a mechanism to manage stakeholders' impressions and to disclose nonfinancial information to the society (Leung, Parker, \& Courtis, 2015, p. 277). CSR reports, together with other forms of professional reports, share an overlapping communicative purpose, that of reporting on events (Bhatia, 2008b, p. 82). Besides, Bhatia (2005) pointed out that a number of institutionalised genres, including academic, political, corporate and many of other reporting genres, are experiencing the invasion of promotional values and the appropriation of non-traditional generic patterns, lexico-grammatical and discoursal resources (p. 8). What's more, Hyland (1998) explored how CEOs try to build a relationship with readers by the use of metadiscourse devices and he identifies three aspects of classical rhetoric appeals that are used to persuade in business reporting genre. Meanwhile, other studies suggest that CSR report, like other kinds of business narratives, is used as a mechanism to manage stakeholders' impressions and to build a positive corporate image (Al-Tuwaijri \& Christensen, 2004; Merkl-Davies \& Brennan, 2007; Loughran \& McDonald, 2011; Luo \& Tang, 2014). All in all, CSR report, as an "embedded" genre (Bhatia, 2005, p. 8), combines informative, promotional and reputation-building purposes at the same time, which fully embodies the characteristics of "hybridity" of business discourse (Bargiela-Chiappini, 2014, p. $68)$.

CSR report has also been studied from a discursive perspective, with an assumption that CSR reporting is a situated action used not only to disclose information but also to construct CSR practice. To date, the number of discursive studies on CSR reports is on the rise, mainly focusing on discourse practice and including a wide range of topics such as genre analysis (Bhatia, 1993; Gillaerts et al., 2011; Cho \&Yoon, 2013; Rutherford, 2013; Rajandran, 2016), critical discourse analysis (Alvesson \& Karreman, 2000; Jenny \& Carlos, 2013; Makela, 2013; Higgins \& Coffey, 2016; Bhatia, 2017) and narrative analysis (Nazari, Hrazdil, \& Mahmoudian, 2017; Wang \& $\mathrm{Li}, 2018)$ etc. For example, Rutherford (2013) applied a genre-theoretic approach to examine features of financial reports and found that the composition of financial statement includes knowing users, an engaged discourse community, situated communication, intertextuality and structural dynamism. Since most CSR reports resemble annual report (Higgins \& Coffey, 2016), the genre features of CSR reports are similar to that of annual report as well. Higgins \& Coffey (2016) started from a critical discourse perspective to explore what CSR reports do and found that companies use CSR report as a dialogue to communicate with stakeholders strategically.

Besides, there are several micro-level analyses to reveal linguistic features of CSR report or annual report. The specific focuses are summarized as follows, such as thematic analysis (Ocler, 2009), discourse connectives analysis (Camiciottoli, 2010), metaphor (Ho \& Cheng, 2016), sentiment analysis (Li, 2011; Twedt \& Rees, 2012; Kang, Park, \& Han, 2017), readability (Laksmana, 2012; Bonsall IV, 2017; Lahtinen, 2017) etc. Ocler (2009) adopted a story-telling approach to examine how firms build and develop corporate discourse to construct a CSR strategy and proved that discourse analysis is a valid method to study CSR communication. Besides, Camiciottoli (2010) investigated the use of discourse connectives in written and spoken financial reports and showed that discourse connectives such as "however", "in addition" serve a range of functions, often foregrounding the positive while attenuating the negative.

There are few studies on CSR reports from the perspective of Appraisal Theory. In the knowledge of the author, only two studies are highly related to present research. Aiezza (2015) took forward-looking statement of CSR reports as research subject and conducted a corpus-assisted discourse analysis of modality and authorial stance in CSR reports. The results show that self-promotion is enacted mainly through optimistic projections and positive modality markers so that an ethical corporate image is created. Another study analyzes the use of evaluative adjectives within letters of the shareholders and finds that the top evaluative adjectives highlight the rhetorical and persuasive purpose of influencing investors into believing in the financial strength and long-term viability of their corporations (Poole, 2017).

To sum up, CSR report, rooted in management, accounting and business communication field, has aroused wide attention in discourse studies in recent decades. Although the number of discursive studies on CSR reports is on the rise, research perspectives are limited. In particular, studies on CSR reports from the perspective of Appraisal 
Theory are rarely seen. Besides, discursive studies on CSR reports mainly focus on letters of shareholders (either CEOs or Presidents), whereas the Management Discourse Analysis (MD \& A) section of CSR reports is rarely mentioned, particularly the various stakeholders' CSR disclosure part. Besides, since corporate social responsibility concerns various stakeholders, previous studies are far from enough to analyze each group of stakeholders individually, such as employees, consumers, community, supply chain etc. In addition, critical analysis of CSR information disclosure is rare. Few researches are concerned with how companies conceptualize each stakeholder and how companies impart their ideology of being a responsible corporate citizen. Lastly, as for research methodology, previous studies mainly adopt qualitative analysis, while more quantitative analyses and empirical studies are needed to enhance existing research findings.

The present study focuses on employee section of CSR report, starting from an intratextually dialogic engagement perspective to explore how and what rhetorical strategies CSR report writers employ to enhance authorial stance and to realize interpersonal meanings. It aims to compare how engagement resources are employed in American and Chinese CSR reports so as to find out the distinctive rhetorical strategies that have been used to achieve communicative purposes. It may be helpful for stakeholders to recognize corporate's ideology and to get a better understanding of CSR information disclosure.

\subsection{Martin's Engagement System}

Voloshinov (1995) states that "The actual reality of language-speech is not the abstract system of linguistic forms, but the social event of verbal interaction implemented in an utterance or utterances" (p. 139). Thus, verbal interaction is the basic reality of language. In other words, all verbal communication, whether written or spoken, is "dialogic" in essence and reflects social reality (Martin \& White, 2005, p. 92). It is the same with reporting genres. Since all texts are dialogic, it is worthwhile considering the negotiation of alignment/disalignment between writer/speaker's stance and the putative addressee's voice or proposition. This study is interested in rhetorical strategies of dialogic engagement resources by which speakers/writers take a stance towards various voices or propositions being referenced by the text and thereby align themselves with those who hold different positions.

In order to explore the rhetorical strategies of dialogic functionality, this study takes Martin's $(1992,1997)$ and Martin and White's (2005) heteroglossic engagement system (as an umbrella term for resources of intersubjective stance) of Appraisal Theory as theoretical foundation. Besides, Stubbs' (1996) category of "modality" is also taken into account to explore speakers/writers' attachment or detachment from alternative propositions.

Martin and White (2005) claimed that engagement is concerned with the ways in which resources such as projection, modality, polarity, concession and various comment adverbials position the speaker/writer with respect to the proposition being advanced by quoting or reporting, acknowledging, denying, countering, affirming a possibility and so on (p. 36), which is construed as a backdrop of prior utterances, alternative viewpoints and anticipated responses (p. 97). Engagement is a dimension where writers acknowledge and connect to others to guide the readers as discourse participants by recognizing the presence of their readers, drawing them along with their arguments, focusing their attention, acknowledging their uncertainties (White, 2003 , p. 268). Specifically, engagement resources can be classified as "dialogically contractive" or "dialogically expansive". The distinction turns on the degree to which an utterance actively makes allowances for dialogically alternative positions and voices (dialogic expansion), or alternatively, acts to challenge, fend off or restrict the scope of such (dialogic extraction) (White, 2003, p. 262).

According to Martin and White's (2005) research of engagement system, specific engagement resources explored in present study are shown in Table 1.

Table 1 demonstrates the category, meaning and discursive markers of engagement resources that have been explored in this study. They are also the wordings and expressions annotated in target corpora. Besides, a broad range of "modality" resources including modal auxiliary, modal adjunct, modal attribute, modal verb and evidential formulations (White, 2008, p. 165) are annotated as well to explore dialogic engagement resources in CSR reports. Therefore, engagement resources in present study are specifically composed of disclaim markers, proclaim markers, entertain markers, attribute markers and modality markers. By analyzing engagement resources, this paper aims to find out how CSR reports writers posit their subjective stances to various alternative propositions so that writer-reader dialogue is formed and interpersonal meanings are achieved. 
Table 1. Summary of engagement resources (Martin \& White, 2005, p. 134)

\begin{tabular}{ll}
\hline Engagement resources & Meanings \\
\hline Dialogic contraction & \\
DISCLAIM & $\begin{array}{l}\text { meanings by which some dialogic alternative is } \\
\text { directly rejected or supplanted. }\end{array}$
\end{tabular}

Markers

Deny

Counter:

PROCLAIM

Concur:

Pronounce:

Endorse:

Dialogic expansion

ENTERTAIN

ATTRIBUTE

Acknowledge:

Distance: a resource for introducing the alternative position into the dialogue first by acknowledging it, then by rejecting it.

formulations which represent the current proposition as replacing, and thereby countering a proposition which would have been expected in its place.

formulations which act to limit the scope of dialogic alternatives in the ongoing colloquy.

formulations which overtly announce the writer/ speaker as agreeing with some projected dialogic partner.

formulations which involve authorial emphases or explicit authorial interventions or interpolations.

formulations which are external voices but agree with the writer/speaker's propositions.

those wordings by which the authorial voice indicates that its position is but one of a number of possible positions and thereby makes dialogic space for those possibilities.

formulations which disassociate the proposition from the text's internal authorial voice by attributing it to some external source.

those locutions where there is no overt indication as to where the authorial voice stands with respect to the proposition.

formulations in which there is an explicit distancing of the authorial voice from the attributed material. no, didn't, never, neither, nor etc.

although, even though, yet, just, only, even, still etc.

of course, naturally, admittedly, certainly etc.

I contend, The facts of the matter are that..., We must agree that... etc.

The report demonstrates/ shows/ proves that...etc.

perhaps, probably, it's likely that, I think/ believe..., it appears..., the research suggests that...etc.

reporting verbs, such as say, report, state, declare, announce....etc.

reporting verbs, 'scare quotes' etc. 


\section{Method}

\subsection{Research Questions}

This paper aims to explore how dialogic engagement resources are employed to construe intersubjective stance and rhetorical strategies that have been used in CSR reports so that communicative purposes can be achieved. With the general purpose, this study tries to find out the answers to the following questions:

1) What are the types of engagement resources and their frequencies employed in American and Chinese CSR reports respectively?

2) Are there any significant differences in the employment of engagement resources in American and Chinese CSR reports?

3) How is interpersonal meaning realized through the employment of engagement resources in two corpora? What distinctive rhetorical strategies do American and Chinese CSR reports writers employ to construe intersubjective stance?

\subsection{Data Collection}

The present research takes 60 employee section CSR reports as research subject, which are all extracted from CSR reports downloaded from 2015 World Fortune Top 500 company's official websites, including 30 CSR reports from American listed corporations and 30 from Chinese listed corporations. All CSR reports are published in English. Employee section CSR reports are excerpted by subheadings (normally reported under the title of "People", "Employees" or "Human Resources"). The target corporations are chosen in terms of their annual total value, ranking from top to bottom and constraining to five industries, namely, Oil \& Gas, Telecommunications, Financials, Industrials and Consumer Services (in terms of "Industry Classification Benchmark", 2001 version). The token of American CSR reports corpus and Chinese CSR reports corpus is 63,581 and 64,075 separately, which is close to each other. Although a limited sample, the chosen companies are seen to represent the majority of publicly listed companies, as they all operate in global market and are exposed to similar market environment, global competition, legislative regulations and societal expectation. Therefore, the present comparative study of Chinese and American CSR reports has its grounds, the research findings of which may give practical implications to Chinese CSR reports writers.

\subsection{Research Procedure and Method}

The two sub-corpora, American CSR report corpus and Chinese CSR report corpus, are processed by corpus investigation program UAM Corpus Tool 3.3 for it comprises a set of tools for linguistic annotation of text and has powerful data processing function, such as token, type, lexical density, percentage and statistical significance test. UAM Corpus Tool is adopted to set up target corpora and process engagement resources in detail.

After 60 employee section CSR reports in TXT. format are imported into UAM Corpus Tool, the coding scheme of engagement resources is designed in terms of Martin and White's (2005) heteroglossic engagement system of Appraisal Theory and is presented in Figure 1. Then the UAM Corpus Tool automatically annotates all specific engagement resources according to the preset coding scheme. In order to ensure the reliability and validity of the coding procedure, the author and another colleague, who is familiar with Martin and White's (2005) Appraisal Theory and discourse semantics, conduct a second annotation manually, with some expressions which aren't engagement markers removed. For example, the word "not" in expression like "not only...but also..." is indeed not a Disclaim-Denial marker, thereby being not annotated. The reliability of two raters' annotation is acceptable, with Cohen's Kappa $=0.84$. A sample annotation is shown in Figure 2.

This study adopts a combined method. Based on target corpora and Chi-Square test, engagement resources in employee section CSR reports are thoroughly examined. Firstly, engagement category and frequency of each engagement marker are carefully counted by UAM Corpus Tool. Then, Chi-Square test is further applied to determine whether the differences in six types (Contract, Expand, Disclaim, Proclaim, Entertain and Attribute, as shown in Table 1) of engagement resources show any statistical significance. Lastly, the specific employment of engagement resources and the realization of interpersonal meaning are analyzed through text analysis and are complemented by cases excerpted directly from target corpora. 


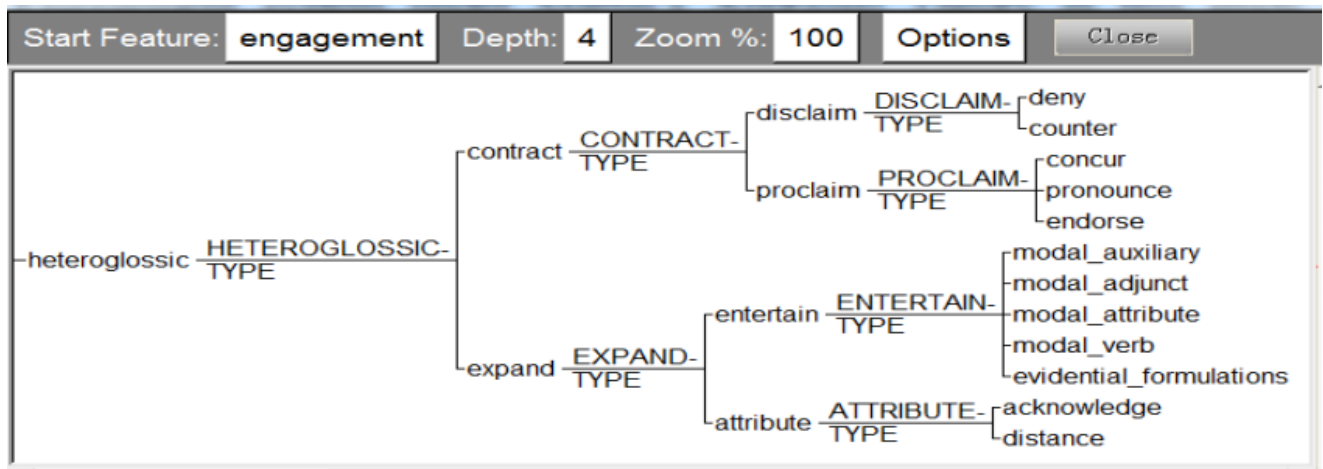

Figure 1. The coding scheme of engagement resources

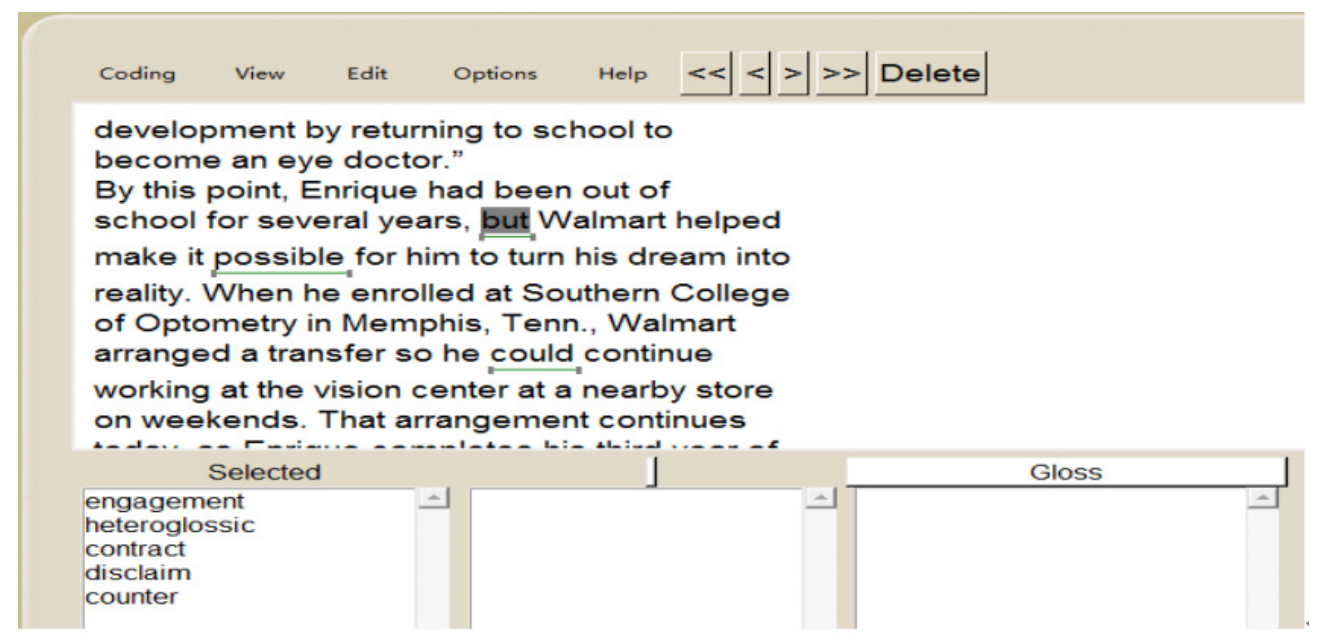

Figure 2. An annotation sample of engagement resources in UAM corpus tool

\section{Findings and Discussion}

\subsection{General Distribution of Engagement Resources in Two Corpora}

The total number of heteroglossic engagement resources in two corpora is 1,497, with frequency in American reports and Chinese reports $795(53.11 \%)$ and $702(46.89 \%)$ respectively. Chi-Square Test of general heteroglossic engagement resources in two corpora shows a statistically significant difference at $p=0.009(<.01)$, with two "**" Therefore, a comparative study of heteroglossic engagement resources between two corpora is valid.

According to the coding scheme, the global descriptive statistics of engagement resources in two corpora is presented in Table 2. From the table, it is found that all types of engagement resources are widely employed in CSR reports genre. Besides, expansion markers occupy an overwhelming majority of all engagement resources, with $59.50 \%$ in American corpus versus $72.79 \%$ in Chinese corpus, suggesting that textual voice in CSR reports genre is represented as entertaining alternative positions and allowing various voices to exist in the same context. In addition, American CSR writers tend to employ much more contraction markers than Chinese writers do, indicating that CSR disclosure of employee in American CSR reports shows much more self-confidence so that they close down space for dialogic alternatives. Finally, as for subtypes of engagement resources, American writers employ slightly more disclaim and proclaim markers than that in Chinese CSR reports, whereas attribute resources are less frequently used. 
Table 2. Distribution and frequency of engagement resources in two corpora

\begin{tabular}{lllll}
\hline \multirow{2}{*}{ Engagement resources } & \multicolumn{2}{l}{ American CSR reports } & \multicolumn{2}{l}{ Chinese CSR reports } \\
\cline { 2 - 5 } & Frequency & Percentage (\%) & Frequency & Percentage (\%) \\
\hline Contract & 322 & 40.50 & 191 & 27.21 \\
Disclaim & 200 & 25.16 & 117 & 16.67 \\
Proclaim & 122 & 15.34 & 74 & 10.54 \\
Expand & 473 & 59.50 & 511 & 72.79 \\
Entertain & 364 & 45.79 & 381 & 54.27 \\
Attribute & 109 & 13.71 & 130 & 18.52 \\
\hline
\end{tabular}

\subsection{The Significant Difference of Engagement Resources in Two Corpora}

The difference in frequency alone doesn't scientifically validate the distinctive features of intersubjective stance in two corpora. In order to verify whether the difference in the employment of engagement resources is significant, Chi-Square test is adopted to further examine the statistical findings. The result of Chi-Square test is shown in Table 3.

Table 3. Chi-square test of engagement resources in two corpora

\begin{tabular}{llll}
\hline Engagement resources & $\begin{array}{l}\text { Frequency in American } \\
\text { CSR corpus }\end{array}$ & $\begin{array}{l}\text { Frequency in } \\
\text { CSR corpus }\end{array}$ & Chinese \\
\hline Contract & 322 & 191 & $34.6134^{* * *}$ \\
Expand & 473 & 511 & 1.1974 \\
Disclaim & 200 & 117 & $22.4350^{* * *}$ \\
Proclaim & 122 & 74 & $12.1484^{* * *}$ \\
Entertain & 364 & 381 & 0.2319 \\
Attribute & 109 & 130 & 1.8704 \\
\hline
\end{tabular}

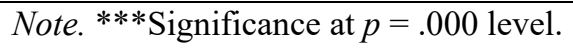

As it is shown in Table 3, for contraction, disclaim and proclaim resources, $p=0.000(<.01)$, demonstrating that contract subsystem are significantly different in two corpora. However, the distribution of expand, entertain and attribute subsystems are not so different in target corpora, which indicates that when construing intersubjective stance American CSR writers tend to contract dialogical space by directly rejecting or supplanting, while Chinese CSR writers tend to shorten writer-reader distance by acknowledging external voices. The difference of the preferred engagement resources in two corpora suggests that the interpersonal cost of realizing interpersonal meaning in American CSR corpus is higher than that in Chinese corpus.

In order to further explore how differently interpersonal meaning is realized through the employment of engagement resources in two corpora, a detailed analysis, especially of contraction resources, is to be scrutinized as follows.

\subsection{The Rhetorical Analysis of Realization of Interpersonal Meaning}

From former analysis, it can be seen that contraction resources distribute significantly different in two corpora. Thus this study mainly takes contraction markers as specific examples to demonstrate how differently engagement resources are employed in two corpora to realize interpersonal meaning.

\subsubsection{Dialogic Contraction Resources}

Dialogic contraction resources are divided into two subsystems Disclaim and Proclaim, which act to reject, counter, confront, head off or rule out actual or potential dialogic alternatives (Martin \& White, 2005, p.117). In present study, the frequency of contraction resources in American and Chinese CSR reports corpora is significantly different. Apart from frequency, to what extent the rhetorical use of contraction resources affects the realization of interpersonal meaning awaits further discussion. In this part, two subsystems of contraction, 
Disclaim and Proclaim, will be analyzed in detail.

\subsubsection{Disclaim Resources}

Firstly, it comes to dialogic disclaim resources. Disclaim resources contain two subtypes: Deny and Counter (Martin \& White, 2005, p. 118). Each formulation has its own functionality to help authorial voice to close down the space for dialogic alternatives so as to align or disalign itself with the construed readers. Disclaim resources act in some way to increase the interpersonal cost to those who would challenge the viewpoint currently being advanced by the text (White, 2003, p. 268). Table 4 shows the highly frequently used disclaim markers in two corpora.

Table 4. High-frequency disclaim markers in two corpora

\begin{tabular}{|c|c|c|}
\hline $\begin{array}{l}\text { High-frequency disclaim } \\
\text { markers }\end{array}$ & $\begin{array}{l}\text { American CSR reports } \\
\text { (Frequency, Percentage \%) }\end{array}$ & $\begin{array}{l}\text { Chinese CSR reports } \\
\text { (Frequency, Percentage \%) }\end{array}$ \\
\hline Deny & $\begin{array}{l}\text { no, never, not, neither, nor, in lack of, without, } \\
\text { rather than }(95,47.50 \%)\end{array}$ & no, never, not $(57,48.72 \%)$ \\
\hline Counter & $\begin{array}{l}\text { although, even though, but, just, yet, } \\
\text { not...but..., not just, even, although...not... } \\
(105,52.50 \%)\end{array}$ & $\begin{array}{l}\text { although, even though, but, just, } \\
\text { yet }(60,51.28 \%)\end{array}$ \\
\hline
\end{tabular}

From Table 4, it can be found that disclaim markers are more diversified and flexible in American CSR reports than that in Chinese CSR reports. Besides, the co-work of Deny and Counter markers is presented mainly in American CSR reports.

(1) No [contract, disclaim, +deny] injuries or impact to the environment occurred as a result of the high or median consequence events. (Marathon Oil, 2015 Social Responsibility Report)

(2) "Without [Contract, disclaim, +deny] your presence, we wouldn't realize our dream of having access to electricity." (China Huaneng Group, 2015 Responsibility Report)

(3) We're proud of the jobs and opportunities we share with our associates but [contract, disclaim, + counter] we knew we could do better. (Walmart, 2015 Global Responsibility Report)

(4) And when succeed, it's because our team of employees succeeds not just [contract, disclaim, + counter] at work, but [contract, disclaim, +counter] in life. (Verizon Communications, 2015 Corporate Responsibility Supplement)

As it is shown in above examples, disclaim resources - Deny and Counter markers are used to realize interpersonal meanings in CSR reports. In Examples (1) and (2), denial markers "no" and "without" are used to entail a direct rejection or countering of a dialogically contrary position so that the positive authorial voice is advocated. In Example (1), it seemingly sets the tone to the readers that there may be possible injuries or impact as a result of the pipe failure. Then, the author employs a denial marker "no" to clearly contradict the addressee's expectation, thereby acknowledging the idea that Marathon Oil is an environmental-friendly firm. In doing so, the interpersonal meaning of reputation building is achieved. Therefore, the contraction denial is dialogic in that it first acknowledges the alternative position and then rejects it.

In Examples (3) and (4), Counter resources "but" and "not just...but..." are used to achieve interpersonal meanings. The countering is typically conveyed via conjunctions and connectives such as "although", "but", "yet" (Martin \& White, 2005, p. 120). Both propositions in samples exert the communicative function of shaping the company as a harmonious and responsible workplace for its employees, regarding companies as families, then employees as family members. In Example (4), the writer firstly admits that Verizon is a place for teamwork, invoking the expectation that Verizon's success is due to talented people's teamwork. Then the counter resources "just" and "but" indicate the expectation is ruled out and stress that Verizon's success is not only due to employees' teamwork but also their loyalty. Through the employment of counter markers, the impression that Verizon is highly responsible for employees is achieved.

The distribution of disclaim resources in two corpora is significantly different, so are rhetorical strategies of realizing interpersonal meanings. Chinese CSR reports writers need to flexibly employ much more diversified 
disclaim markers as American writers do. Besides, the co-work of Deny and Counter resources is widely used in American CSR corpus, while it is rarely seen in Chinese CSR reports. This rhetorical employment of Deny and Counter resources can enhance a countering effect by which the disalignment between textual voice and other alternative propositions is mitigated. By doing so, the intersubjective stance is maintained.

\subsubsection{Proclaim Resources}

Under dialogic contraction system, proclaim resources share a functionality with a set of wordings which perhaps more obviously represent the textual voice as taking up some generally held position and thereby as concurring with the reader (White, 2003, p. 269). Proclaim means dialogic alternatives are confronted, challenged, overwhelmed or otherwise excluded through some authorial interpolation, emphasis or intervention (Martin \& White, 2005, p. 121). Proclaim subsystem can be divided into three subtypes: Concur, Pronounce and Endorse. Table 5 shows the high frequency proclaim resources in two corpora.

Table 5. High-frequency proclaim markers in two corpora

\begin{tabular}{lll}
\hline $\begin{array}{l}\text { High-frequency } \\
\text { proclaim markers }\end{array}$ & $\begin{array}{l}\text { American CSR reports } \\
\text { (frequency, percentage \%) }\end{array}$ & $\begin{array}{l}\text { Chinese CSR reports } \\
\text { (frequency, percentage \%) }\end{array}$ \\
\hline Concur & $\begin{array}{l}\text { clearly, admittedly, of course, naturally, } \\
\text { obviously, make sure, sure, it is clear that... } \\
(58,47.54 \%)\end{array}$ & $\begin{array}{l}\text { affirm, naturally, of course, it is } \\
\text { obvious that...(19, 25.68\%) }\end{array}$ \\
Pronounce & $\begin{array}{l}\text { The fact is that..., I contend that..., we can } \\
\text { conclude that... (35, 28.69\%) }\end{array}$ & $\begin{array}{l}\text { Really, indeed ....(39, 52.70\%) } \\
\text { Endorse }\end{array}$ \\
\hline
\end{tabular}

From Table 5, we can see that under proclaim subsystem, Concur markers occupy the most in American corpus, while Pronounce markers are the most in Chinese corpus. Besides, Endorse markers take the lowest density in both corpora. The difference in frequency shows American and Chinese CSR reports writers have different rhetorical preferences in the employment of proclaim resources to realize interpersonal meanings. The following examples show a detailed analysis of the realization of interpersonal meanings by the use of proclaim resources.

(5) If the household could grow up under financial support, it would certainly [contract, proclaim, + concur] drive the development of other farmers and play the role of a pacesetter. (Agriculture Bank of China, 2015 Corporate Social Responsibility Report)

(6) "I love the fact that [contract, proclaim, + pronounce] I was given a project to take on as my own, and was entrusted to complete a project in its entirety." (Valero Energy, 2015 Corporate Social Responsibility)

(7) Our participation in the initiative since its founding in 2000 demonstrates [contract, disclaim, +endorse] our longstanding commitment to critical security and human rights issues. (Chevron, 2015 Corporate Social Responsibility)

Examples (5), (6) and (7) contain Concur, Pronounce and Endorse markers respectively. In Example (5), the writer's use of Concur marker "certainly" construes an audience who share the writer's highly positive estimation that households receiving ABC's financial support drive the development of other farmers. Thus, it excludes any other dialogic alternatives from the ongoing colloquy.

Pronounce resource involves authorial emphases, explicit authorial interventions or interpolations (Martin \& White, 2005, p. 127). In Example (6), the writer firstly admits that there is a counter viewpoint that interns are impossible to be given a project alone. Then, the formulation "I love the fact that..." inserts an explicit authorial voice to make an intervention into the text so as to insist upon the warrantability of the proposition. In this case, the authorial voice challenges the particular countering viewpoint. Thus, the interpersonal cost for anyone who wants to support the contrary idea is increased and the dialogic space for this alternative in any upcoming dialogic interaction is reduced. It is the same with Example (7), in which the author uses endorsement word "demonstrate" to ensure the warrantability of Chevron's commitment to employees' security and rights. The 
writer doesn't refer to any other external voices, but the company's participation in the initiative, which actually provides the grounds for the speaker/writer to presuppose this warrantability. White (2003) maintains that Pronounce involves the foregrounding of the subjective involvement of the textual voice (p. 270). By providing the external sources as foregrounds, the authorial stance is maximally verified.

In summary, the employment of both disclaim and proclaim resources in American corpus is more diversified and flexible than that in Chinese corpus, thereby showing a more solid and rich interpersonal meanings of shaping employee image in corporate social responsibility field.

\subsubsection{Dialogic Expansion Resources}

Apart from dialogic contraction, the other type of heteroglossic engagement resources is dialogic expansion, which opens up the dialogic space for alternative positions (Martin \& White, 2005, p. 103). There are two primary modes of dialogic expansion, namely, Entertain and Attribute. The difference of the frequency of expansion resources in American and Chinese CSR corpora is not statistically significant, but they occupy a high proportion of all engagement resources. They all contribute to writer-reader interaction and the realization of interpersonal meanings.

Entertain, being covered in the literature under the headings of "epistemic modality" and "evidentiality" (Palmer, 1986; White, 2008), indicates that the authorial voice is one of a number of possible propositions and therefore to some degree leaves dialogic space for other possibilities. Entertain is a semantic domain by which speaker/writer makes assessment of likelihood via modal auxiliaries (may, might, could, must, etc.), modal adjuncts (perhaps, probably, definitely, etc.), modal attributes (it's possible that..., it's likely that...etc.), mental verbs (suspect, think, believe, etc.) and evidential formulations (it seems, it appears, apparently the research suggests...etc.) (Martin \& White, 2005, p. 105). After testing these five types of Entertain resources in two corpora, it is found that the frequency of modal adjunct resources and modal attribute resources is significantly different in two corpora, with a much higher proportion in Chinese CSR corpus than that in American corpus. Examples (8) and (9) below show how modal adjunct and modal attribute markers are used to open dialogic space for alternative voices so that interpersonal meanings are realized.

(8) I will definitely [expand, entertain, +modal adjunct] hold up half of the sky of the office. (China National Petroleum, 2015 Corporate Social Responsibility Report)

(9) It is likely [expand, entertain, + modal attribute] to accelerate the training of newly recruited university graduates and help the new employees get merged into their teams as soon as possible. (Agricultural Bank of China, 2015 Corporate Social Responsibility Report)

In Examples (8) and (9), entertain markers "definitely" and "it is likely..." are used to allow space for alternative proportions and express different degree of assertion. For instance, in Example (9), although the company headquarter has issued the training plan, the writer hasn't known whether it will be implemented right now or not. Therefore, the writer uses a modal attribute "it is likely..." to leave dialogic space for readers to negotiate and to challenge his viewpoint. The proportion indicates that the authorial voice is construed as one of a range of alternative propositions.

Another difference in expressing intersubjective stance is attribute resources. Attribution deals with those formulations which disassociate the proposition from the text's internal authorial voice by attributing it to some external source (Martin \& White, 2005, p. 111). This effect is achieved through the employment of directly and indirectly reported speech and thought. Attribute resources have two subtypes, namely, Acknowledge and Distance. The frequency of attribute resources in Chinese CSR corpus is slightly higher than that in American corpus, with Acknowledge markers $14.62 \%$ versus $10.84 \%$ and Distance markers $3.48 \%$ versus $2.44 \%$. Next part mainly focuses on Ackonwledge markers and its collocation in two corpora.

Acknowledge markers refer to those locutions which show that the authorial voice is neutral or unspecified concerning the proposition. It is realized through reporting verbs such as "report", "state", "declare", "announce" etc. Besides, some adverbial adjuncts are also regarded as Acknowledge resources such as "in X's view", "according to", "X believes/ argues/asserts that..." (Martin \& White, 2005, p. 112). The following Example (10) illustrates how Acknowledge resources are used to engage authorial voice with other external propositions.

(10) As he put it [expand, attribute, +acknowledge], every service station is the extension of the ABC outlets and the head of every farmer household shop is the off staff "employee" of $\mathrm{ABC}$ that representing the image of ABC. (Agriculture Bank of China, 2015 Corporate Social Responsibility Report)

Example (10) shows how the external propositions are used to present authorial voice as engaging interactively with those voices. In Example (10), the pronoun "he" in phrase "as he put it" refers to the Company Secretary 
who is one of the authoritative leaders in $\mathrm{ABC}$. The citation indicates that the authorial voice agrees with this particular external voice so as to align readers with this viewpoint as well. By doing so, the distance between writer and reader is contracted and the idea that employee is an integral part of ABC is conveyed as well, so that interpersonal meaning is realized.

Indeed, based on a careful observation of Acknowledge resources in two corpora, it finds that the sources of Acknowledgement in Chinese CSR report are either board members, company authoritative leaders or company provisions, while American CSR reports writers tend to cite diversified external sources like authoritative study, scientific research, examples, editorial, newspaper, voices of leaders/employees etc. Thus it suggests that the external sources of Acknowledgment resources are different in American and Chinese CSR reports.

\section{Conclusion}

This study takes English-version employee section CSR reports of American and Chinese listed corporations as research subject. Based on corpus analysis, this research focuses on how CSR reports writers posit their authorial voices to align putative readers by the use of engagement resources. Meanwhile, it explores how interpersonal meaning of CSR reports is realized and what different rhetorical strategies are employed in American and Chinese CSR reports. By the application of UAM Corpus Tool and Chi-Square test, the frequency and significance level of engagement resources are tested. Then, how engagement resources are employed to realize interpersonal meaning is explored and distinctive rhetorical strategies are summarized.

We firstly find that four subsystems of engagement resources of disclaim, proclaim, entertain and attribute are all used in both American and Chinese CSR reports to achieve communicative purposes. Despite this, expansion resources are much more widely used in both corpora than contraction resources. Besides, the difference of contraction resources in two corpora is statistically significant, while that of expansion resources is not.

As for distinctive rhetorical strategies to realize interpersonal meaning, firstly, American CSR reports employ each type of engagement resources in an almost balanced number, while Chinese CSR reports deploy expansion resources approximately three times as many as contraction resources, suggesting that less interpersonal cost is needed when interpreting Chinese CSR reports. Secondly, as for contraction resources, American CSR reports employ more diversified and flexible Disclaim and Proclaim resources than Chinese reports. For Disclaim resources, American reports use as many as Chinese reports, especially the Deny-Counter pairings being widely employed to achieve interpersonal meanings. For Proclaim resources, Concur markers are preferred in American CSR reports, while Pronounce markers occupy the most in Chinese CSR reports. Thirdly, Chinese CSR reports employ expansion resources appropriately $15 \%$ more than that in American reports, meaning that Chinese writers tend to acknowledge corporate authorities as external voices to enhance intersubjective stance. Finally, referring to difference in external voices, it specifically describes that Chinese CSR reports usually acknowledge upper leaders, provisions of corporations and other authorities as external voices, while American CSR reports employ diversified external sources such as scientific researches, newspapers, employees' remarks, sayings etc.

This study confirms that engagement resources are important tools employed to construe intersubjective stance and to realize interpersonal meanings in CSR report genres. What's more, the extensive use of all subsystems of engagement resources in two corpora contributes to shape CSR reports as what Bhatia called "promotional genres". The findings firstly suggest that Chinese CSR reports writers should fully employ each type of engagement resources to help close writer-reader distance as American counterparts do. Then, they are suggested to deploy the integration of contraction and expansion markers in a more diversified and flexible way so as to persuade readers more effectively and to build up a positive corporate image in a more positive way. In addition, Chinese CSR reports writers are recommended to acknowledge a more diversified source of external voices rather than only focus on corporate authorities. Besides, this study may shed light on CSR reports addressers and addressees. It could also give some pedagogical implications to business English teaching and reading.

\section{Acknowledgements}

This paper is supported by the postgraduate scientific research fund approved by Xi'an International Studies University (syjsb201708) and key research project of university-level approved by Xi'an International Studies University (17XWZD04).

\section{References}

Aiezza, M. C. (2015). "We may face the risks'... 'Risks that could adversely affect our face': A corpus-assisted discourse analysis of modality markers in CSR." Studies in Communication Sciences, 10, 1-9. https://doi.org/ 10.1016/j.scoms.2015.03.005

Al-Tuwaijri, S. A., \& Christensen, T. E. (2004). The relations among environmental disclosure, environmental 
performance, and economic performance: A simultaneous equations approach. Accounting of Organization \& Society, 29(5), 447-471. https://doi.org/10.1016/S0361-3682(03)00032-1

Alvesson, M., \& Karreman, D. (2000). Taking the linguistic turn in organizational research: Challenges, responses, consequences. The Journal of Applied Behavioral Science, 36(2), 136-58. https://doi.org/10.1177/00218 86300362002

Bargiela-Chiappini, F. (2014). Business Discourse (2nd ed.). Basingstoke: Palgrave Macmillan.

Bhatia, V. K. (1993). Analyzing Genre: Language in Professional Settings. London: Longman.

Bhatia, V. K. (2005). Generic patterns in promotional discourse. In V. K. Bhatia, (Ed.), Persuasion across Genres: A Linguistic Approach (pp. 213-228). Amsterdam: John Benjamins Publishing Company. https://doi.org /10.1075/pbns.130.13bha

Bhatia, V. K. (2008a). Towards critical genre analysis. In V. K. Bhatia, J. Flowerdew, \& R. Jones (Eds.), Advances in Discourse Studies (pp. 166-177). London: Routledge.

Bhatia, V. K. (2008b). Worlds of Written Discourse: A Genre-based View. Shanghai: Shanghai Foreign Language Education Press.

Bhatia, V. K. (2017). Critical Genre Analysis: Investigating Interdiscursive Performance in Professional Practice. New York: Routledge.

Bonsall IV, S. B., Leone, A. J., Miller, B. P., \& Rennekamp, K. (2017). A plain English measure of financial reporting readability. Journal of Accounting and Economics, 63, 329-357. https://doi.org/10.1016/j.jacceco. 2017.03.002

Camiciottoli, B. C. (2010). Discourse connectives in genres of financial disclosure: Earnings presentations vs. earnings releases. Journal of Pragmatics, 42, 650-663. https://doi.org/10.1016/j.pragma.2009.07.007

Cho, H., \& Yoon, H. (2013). A corpus-assisted comparative genre analysis of corporate earnings calls between Korean and native-English Speakers. English for Specific Purposes, 32, 170-185. https://doi.org/10.1016/ j.esp.2013.03.001

Eccles, R. G., \& Krzus, M. P. (2010). One report: Integrated reporting for a sustainable strategy. Hoboken: John Wiley \& Sons, Inc. https://doi.org/10.1371/journal.pone.0010528

Gillaerts, G., Groot, E., Dielejens, S., Heynderickx, P., \& Jacobs, G. (2011). Researching discourse in business genres: Cases and corpora. Bern/New York: Peter Lang.

Googins. B. K., Philip, M., \& Rochlin, S. A. (2006). Stage of corporate citizenship. California Management Review, 48(2), 104-126. https://doi.org/10.1057/9780230609983_6

Gray, R. (2006). Social, environmental and sustainability reporting and organizations value creation? Whose value? Whose creation? Accounting Auditing \& Accountability Journal, 19(6), 793-819. https://doi.org/10.1108/09513570610709872

Hackston, D., \& Milne, M. J. (1996). Some determinants of social and environmental disclosures in New Zealand companies. Accounting, Auditing \& Accountability Journal, 9(1), 77-108. https://doi.org/10.1108/ 09513579610109987

Higgins, C., \& Coffey, B. (2016). Improving how sustainability reports drive change: A critical discourse analysis. Journal of Cleaner Production, 136, 18-29. https://doi.org/10.1016/j.jclepro.2016.01.101

Ho, J., \& Cheng, W. (2016). Metaphors in financial analysis reports: How are emotions expressed? English for Specific Purposes, 43, 37-48. https://doi.org/10.1016/j.esp.2016.04.001

Hyland, K. (1998). Exploring corporate rhetoric: Metadiscourse in the CEO's letter. Journal of Business Communication, 35(2), 224-245. https://doi.org/10.1177/002194369803500203

Hyland, K. (2005). Metadiscourse: Exploring Interaction in Writing. London/New York: Continuum.

Jenny, G., \& Carlos, N. (2013). Corporate social responsibility reporting research in the Chinese academia: A critical review. Social Responsibility Journal, 9, 33-55. https://doi.org/10.1108/174711111311307804

Kang, T., Park, D. H., \& Han, I. (2017). Beyond the numbers: The effect of 10-K tone on firms' performance predictions using text analytics. Telematics and Informatics, 12(16), 1-28. https://oi.org/10.1016/ j.tele.2017.12.014

Lahtinen, K. D., \& Shipe, S. (2017). Readability of financial advisor disclosure. Journal of Empirical Finance, 44, 
50-61. https://doi.org/10.1016/j.jempfin.2017.08.002

Laksmana, I., Tietz, W., \& Yang, Y. W. (2012). Compensation discussion and analysis (CD\&A): Readability and management obfuscation. Journal of Accounting \& Public Policy, 3, 185-203. https://doi.org/10.1016/j. jaccpubpol.2011.08.003

Leung, S., Parker, L., \& Courtis, J. (2015). Impression management through minimal narrative disclosure in annual reports. British Accounting Review, 47(3), 275-289. https://doi.org/10.1016/j.bar.2015.04.002

Li, F. (2011). Textual analysis of corporate disclosures: A survey of the literature. Journal of Accounting Review, 29, 143-165. https://doi.org/10.1016/j.irfa.2014.02.006

Loughran, T., \& McDonald, B. (2011). When is a liability not a liability? Textual analysis, dictionaries, and 10-ks. Journal of Finance, 1, 35-65. https://doi.org/10.1111/j.1540-6261.2010.01625.x

Luo, L., \& Tang, Q. (2014). Does voluntary carbon disclosure reflect underlying carbon performance? Journal of Contemporary Accounting \& Economics, 10(3), 191-205. https://doi.org/10.1016/j.jcae.2014.08.003

Makela, H. (2013). On the ideological role of employee reporting. Critical Perspectives on Accounting, 24, 360-378. https://doi.org/10.1016/j.cpa.2012.11.004

Martin, J. R. (1992). English Text: System and Structure. Amsterdam: Benjamins. https://doi.org/10.1075/z.59

Martin, J. R. (1997). Register and genre: Modelling social context in functional linguistics- narrative genres. In E. R. Pedro (Eds), Discourse Analysis: Proceedings of First International Conference on Discourse Analysis (pp. 305-344). Lisbon: Colibri/Portuguese Linguistics Association.

Martin, J. R., \& White, P. R. R. (2005). The Language of Evaluation. New York: Palgrave Macmillan.

Merkl-Davies, D. M., \& Brennan, N. M. (2007). Discretionary discourse strategies in corporate narratives: Incremental information or impression management? Journal of Accounting Literature, 26, 116-196. https://doi.org/10.3386/w19846

Nazari, J. A., Hrazdil, K., \& Mahmoudian, F. (2017). Assessing social and environmental performance through narrative complexity in CSR reports. Journal of Contemporary Accounting \& Economics, 13, 166-178. https://doi.org/10.1016/j.jcae.2017.05.002

Ocler, R. (2009). Discourse analysis and corporate social responsibility: A qualitative approach. Society and Business Review, 4(3), 175-186. https://doi.org/10.1108/17465680910994182

Palmer, F. R. (1986). Mood and Modality. Cambridge: Cambridge University Press.

Podnar, K. (2008). Communicating corporate social responsibility. Journal of Marketing Communications, 14(2), 75-81. https://doi.org/10.1080/13527260701856350

Poole, R. (2017). "New opportunities" and "strong performance": Evaluative adjectives in letters to shareholders and potential for pedagogically-downsized specialized corpora. English for Specific Purposes, 47, 40-51. https://doi.org/10.1016/j.esp.2017.03.003

Rajandran, K. (2016). Corporate involvement brings environmental improvement: The language of disclosure in Malaysian CSR reports. Social Responsibility Journal, 12(1), 130-146. https://doi.org/10.1108/SRJ $-02-2015-0030$

Rutherford, B. A. (2013). A genre-theoretic approach to financial reporting research. The British Accounting Review, 45, 297-310. https://doi.org/10.1016/j.bar.2013.06.006

Spence, C. (2009). Social accounting's emancipatory potential. Critical Perspectives on Accounting, 20(2), 205-227. https://doi.org/10.1016/j.cpa.2007.06.003

Stubbs, M. (1996). Towards a modal grammar of English: A matter of prolonged fieldwork. In M. Stubbs (Eds.), Text and Corpus Analysis. Oxford: Blackwell.

Twedt, B., \& Rees, L. (2012). Reading between the lines: An empirical examination of qualitative attributes of financial analysts' reports. Journal of Accounting \& Public Policy, 3, 1-21. https://doi.org/10.1016/j. jaccpubpol.2011.10.010

Voloshinov, E. (1995). Marxism and the Philosophy of Language, Bakhtinian Thought: An Introductory Reader (S. Dentith., L. Matejka \& I. R. Titunik Trans.). London: Routledge.

Wang, L. F., \& Li, J. Y. (2018). A comparative study on measuring English discourse complexity of Chinese and US bank reports. Foreign Language and Literature Research, 1, 92-100. 
White, P. R. R. (2003). Beyond modality and hedging: A dialogic view of the language of intersubjective stance. Text, 23(2), 259-284. https://doi.org/10.1515/text.2003.011

White, P. R. R. (2008). Modality as dialogue: A Bakhtinian reanalysis of epistemic stance. Word, 59, 143-167. https://doi.org/10.1080/00437956.2008.11432584

\section{Copyrights}

Copyright for this article is retained by the author(s), with first publication rights granted to the journal.

This is an open-access article distributed under the terms and conditions of the Creative Commons Attribution license (http://creativecommons.org/licenses/by/4.0/). 